\title{
A Crossplot for Mud Logging Interpretation of Unconventional Gas Shale Reservoirs and its Application
}

\author{
Wen-rui Shi ${ }^{1, \#}$, Chong Zhang ${ }^{1,2, *, \#}$, Shao-yang Yuan ${ }^{1}$, Yu-long Chen ${ }^{1}$ and Lin-qi Zhu ${ }^{1}$ \\ ${ }^{1}$ Geophysics and Oil Resource Institute of Yangtze University, Wuhan, Hubei, 430100, China; ${ }^{2}$ Oil and Gas Resources \\ and Exploration Technology Laboratory of the Ministry of Education, Yangtze University, Wuhan, Hubei, 430100, \\ China
}

\begin{abstract}
The drilling time data of gas logging are used to calculate drilling time ratio of the reservoir, and the total hydrocarbon data are used to calculate hydrocarbon contrast coefficient and to establish the drilling time ratio--hydrocarbon contrast coefficient crossplot. The standards of distinguishing the boundaries of hydrocarbon zones, hydrocarbonaceous water layers and dry layers are determined according to the statistics of regional oil testing data. Based on the standards, the crossplot is divided into three areas: hydrocarbon zone, hydrocarbonaceous water layer and dry layer, which are used in mud logging interpretation of abnormal shows in oil and gas layers. This method is widely used for low-resistivity reservoirs, fracture reservoirs, shale gas layers, and especially in the oil and gas zone with weak show and a single component. It is more applicable and accurate than some conventional interpretation methods such as the triangle plot, PIXLER plot, dual light hydrocarbon alkyl ratio and hydrocarbons ratio $(3 \mathrm{H})$.
\end{abstract}

Keywords: Crossplot, drilling time ratio, gas logging, hydrocarbon contrast coefficient, interpretation, unconventional oil and gas.

\section{PREFACE}

The success of the U.S. shale gas revolution has made the rapid growth of the US natural gas production. It changes the energy market in the United States and affects the global energy structure as well. Inspired by the successful experience of shale gas and price reduction of natural gas, the United States has introduced new technologies and experience of shale gas development into the low permeability shale and related series of oil resources which was once considered as no commercial development value. It is called tight oil [1-7]. Like shale gas, therefore, tight oil development success has aroused the concern of our country. Tight oil exploration and production of unconventional energy has become a hot topic. For unconventional energy exploration and production, gas logging is an important way to obtain the drilling time and gas component data in drilling, which can be used in the interpretation of reservoir fluid properties with abnormal gas shows.

\section{PROBLEM POSING}

How to find oil and gas show quickly and how to evaluate fluid properties during drilling has always been a problem concerned by global oil professionals. It is well known that gas logging is a rapid measurement way to find oil reservoirs in drilling site based on analyzing the content and

*Address correspondence to this author at the No.111 University Road, Caidian District, Wuhan, China, Post Code: 430100; Tel: 15090830973; E-mail: zhangc012@yangtzeu.edu.cn

\#Wen-rui Shi \& Chong Zhang contributed equally to this work and should be considered co-first authors. components of hydrocarbon compounds and other natural gases. It is usually called gas logging. It has been widely used as it has advantages of great real time, low cost and simple measurement, but there are some shortcomings in few measurement items, insufficient application of data and limited means of quantitative evaluation of the reservoir. Because gas logging is to measure whether there is hydrocarbon gas in circulating mud while drilling, it is also called mud logging.

There is almost natural gas in oil layers, gas layers and some water layers under the natural state, where natural gas exits in the form of dissolution. While crude oil and formation water carrying dissolved gas return to the surface during drilling, natural gas will spread into the mud. Natural gas in the gas layers is usually in gas state, and liquid-state gas will gasify when returning from bottom hole to the ground, existing in gas state. Therefore, natural gas can be detected by gas instrument whether it is in any state when it returns to the ground with mud, and reservoir fluid properties can be evaluated through analyzing the difference in quantity and component of them. Usually oil-layer gas has higher heavy hydrocarbon content than gas layer, and contains some large molecular hydrocarbon compound gases. Modern gas logging uses high sensitivity automatic chromatographic gas instrument which uses chromatography to separate the takenoff gases. They are measured by hydrogen flame ionization detector or thermal conductivity cell, then the content and component of hydrocarbon gases and non-hydrocarbon gases are analyzed. It has high sensitivity, wide linear range and high automation. It is more sensitive than conventional logging and MWD/LWD. Although the gas drilling time is affected by many factors, drilling fluid system and engineering 
parameters which affect the drilling time are stable relatively in the target interval. Under the condition of no abnormal high pressure, the porosity and lithology of a reservoir are the major factor. The relative change of drill ratio can reflect the change of porosity and lithology at the same time, so the reservoir can be recognized accordingly, and even the reservoir porosity can be quantitatively calculated. Similarly, under the condition of stable drilling fluid system and no added oil (hydrocarbon), the hydrocarbon content from gas logging can reflect the oil-gas possibility of the reservoir. The relative changes also mean that hydrocarbon contrast coefficient can represent the oil-gas possibility preferable, and even the oil and gas saturation can be quantitatively calculated.

The conventional methods for reservoir fluid property evaluation in gas logging and mud logging are triangular plot, PIXLER plot, dual light hydrocarbon alkyl ratio and hydrocarbons ratio ( $3 \mathrm{H}$ method) $[8,9]$. All of these methods require complete gas composition, and the $\mathrm{C}_{3}$ absolute percentage is more than $0.01 \%$ at least. They are not applicable for identifying the gas show layers with a single component. The interpretation coincidence rate is low and poor flexibility for lack of the drilling time data which can reflect porosity and permeability.

According to the situation of low coincidence rate and inadaptability of the traditional methods, a fast interpretation method for reservoir fluid evaluation is proposed in this paper. It is adapted for unconventional oil and gas logging interpretation.

\section{CROSSPLOT INTERPRETATION}

\subsection{Basic Principle}

Drilling time is the basic information parameter provided by geological logging, which is worthy for identification and prediction of abnormal high pressure reservoir [8]. Under the condition of relatively stable drilling parameters, the formation porosity can be speculated based on the decrease of drilling time or increasing of drilling time ratio. RROP (drilling time ratio) is the ratio of the adjacent cap rock drilling time $\operatorname{ROP}_{\mathrm{n}}(\mathrm{min} / \mathrm{m})$ and the reservoir minimum effective drilling time $\mathrm{ROP}_{\mathrm{s}}$, which can reflect the relative changes of reservoir space. It is a logging derivative parameter reflecting the reservoir porosity qualitatively.

Hydrocarbon parameters are the information provided by gas logging which are most relative to gas accumulation [8]. Hydrocarbon contrast coefficient $\mathrm{K}_{\mathrm{c}}$ means the ratio of show layer's total hydrocarbon or methane abnormal value $\mathrm{C}_{t}$ and cap rock's total hydrocarbon or methane value $C_{b}$. It reflects the relative changes of gas accumulation in the reservoir.

As drilling time ratio reflects porosity and permeability characteristics, and hydrocarbon contrast coefficient reflects oil-gas possibility of the reservoir, drilling time ratio and hydrocarbon contrast coefficient crossplot method can be used to identify and evaluate the fluid properties of the hydrocarbon show layers to establish RROP- $\mathrm{K}_{\mathrm{c}}$ crossplot which horizontal axis is the drilling time ratio RROP and vertical axis is the hydrocarbon contrast coefficient $K_{c}$. The plot is divided into three areas: hydrocarbon reservoir, hydrocarbonaceous water layer and dry layer, which are used to characterize interpretation results.

\subsection{Interpretation Standard}

Through statistics of the regional data which have been proved to be hydrocarbon zone, hydrocarbonaceous water layer and dry layer by oil testing, the data points are plotted in $\mathrm{RROP}-\mathrm{K}_{\mathrm{c}}$ chart. The boundaries between reservoir and non-reservoir, hydrocarbon zone and hydrocarbonaceous water layer are determined according to the statistical principles. These two boundaries divide the chart into three areas: hydrocarbon zone, hydrocarbonaceous water layer and dry layer.

\section{CROSSPLOT MAPPING}

\subsection{Establishment Method}

The reservoir fluid properties and hydrocarbon shows are distinguished quickly with gas logging data such as drilling time, total hydrocarbon, hydrocarbon components which are acquired and recorded by gas logging, compound logging instrument and other mud logging equipment. Drilling time ratio and hydrocarbon contrast coefficient crossplot interpretation process is shown below (Fig. 1). Concrete implementation steps are as following:

1) Read the drilling time $\mathrm{ROP}_{\mathrm{s}}$ of the reservoir, take its minimum effective value, then remove the data affected by making up joints;

2) When selecting drilling time data of $5 \mathrm{~m}$ to $20 \mathrm{~m}$ above the reservoir cap rock, get the initial average $\mathrm{ROP}_{\mathrm{n} 1}$ first, then remove the data which are greater than or equal to the mean value of 1.5 times or less than or equal to the initial average value of 0.5 times, calculate the mean value $\mathrm{ROP}_{\mathrm{n} 2}$ of drilling time again, choose $\mathrm{ROP}_{\mathrm{n} 2}$ value as the cap rock drilling time $\mathrm{ROP}_{\mathrm{n}}$;

3) Take the largest virtual value of total hydrocarbon anomalous value $\mathrm{C}_{\mathrm{t}}(\%)$, remove the data affected by making up joints and tripping;

4) Choose the total hydrocarbon mean value of $5 \mathrm{~m}$ to $20 \mathrm{~m}$ above the reservoir cover namely base value $\mathrm{C}_{\mathrm{b}}(\%)$ or known hydrocarbonaceous water layer anomalous value;

5) Use the cap rock drilling time $\mathrm{ROP}_{n}$, reservoir drilling time $\mathrm{ROP}_{\mathrm{s}}$ to calculate the reservoir drilling time ratio $\mathrm{RROP}, \mathrm{RROP}=\mathrm{ROP}_{\mathrm{n}} / \mathrm{ROP}_{\mathrm{s}}$;

6) Use total hydrocarbon anomalous value $\mathrm{C}_{\mathrm{t}}(\%)$ and base value $\mathrm{C}_{\mathrm{b}}(\%)$ to calculate hydrocarbon contrast coefficient $\mathrm{K}_{\mathrm{c}}, \mathrm{K}_{\mathrm{c}}=\mathrm{C}_{\mathrm{t}} / \mathrm{C}_{\mathrm{b}}$;

7) Make regional statistics of the data of hydrocarbon zone, hydrocarbonaceous water layer and dry layer which are proved by oil testing. The data points are plotted in RROP- $\mathrm{K}_{\mathrm{c}}$ chart. According to data statistic principle, the evaluation boundaries are determined which divide the chart into three areas: hydrocarbon zone, water layer and dry layer;

8) Put the data points in RROP- $K_{c}$ chart. The area where data points appear is the evaluation result of the relevant fluid. 


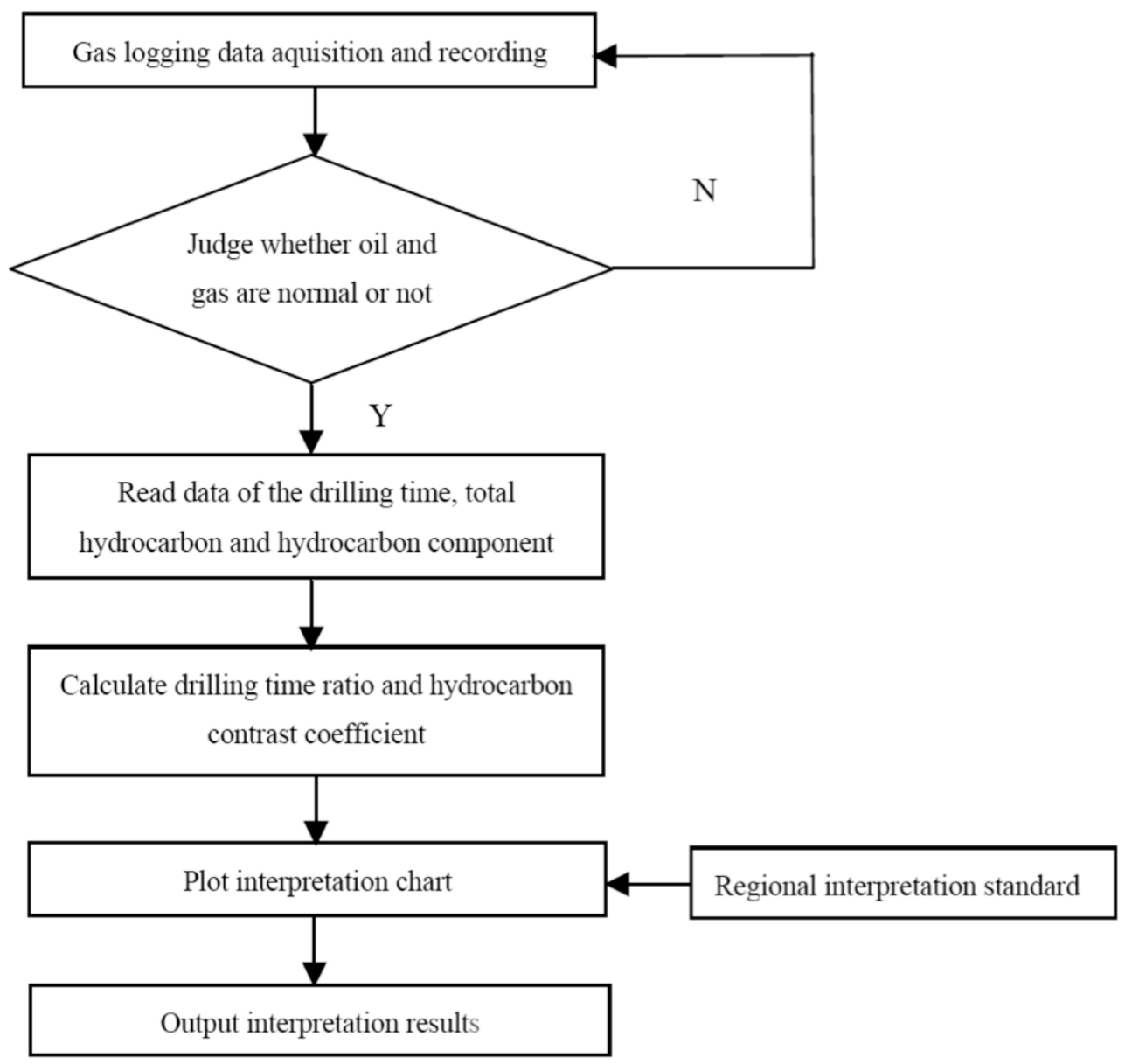

Fig. (1). Drilling ratio and hydrocarbon contrast coefficient crossplot interpretation process.

\subsection{Applicable Conditions}

Like other interpretation cross-plots, RROP- $\mathrm{K}_{\mathrm{c}}$ crossplot has its applicable conditions.

1) Avoiding bit variation effect. Cap rock drilling time $\left(\mathrm{ROP}_{n}\right)$ and reservoir drilling time $\left(\mathrm{ROP}_{\mathrm{s}}\right)$ values need to be read under the condition of same type bit to avoid the effect of grinding shoes (casing shoe) and frequent change of drilling engineering parameters. In the target zone, these factors generally do not occur. When reading drilling time value under the condition of the same type of drill bit, drilling engineering parameters do not change obviously.

2) Avoiding mud system variation effect. Total hydrocarbon or methane anomaly value $C_{t}$ and base value $C_{b}$ are easily affected by the mud density and viscosity, and more susceptible to miscible oil. Generally speaking, mud system is not allowed to transform in drilling engineering even if mud performance is stable in the objective interval. Total hydrocarbon or methane values should be the measured value in the same mud system.

3) Avoiding the effect of gas instrument malfunction and engineering accidents. The total hydrocarbon and hydrocarbon component values measured under the conditions of gas logging instrument malfunction and engineering accident are not reliable.

\section{CASES}

The main constituent of natural gas in unconventional hydrocarbon zone of Jianghan oilfield is methane, and the proportion of ethane and other heavy hydrocarbon approaches $0 \%$. The conventional methods for logging identification works under the condition that the content of ethane and other heavy hydrocarbon is more than $0.01 \%$. They are not applicable for identifying the gas show layers with only a single component, the coincidence rate of interpretation is low. RROP-Kc crossplot method did statistics for lots of boundaries data of hydrocarbon zone, hydrocarbonaceous water layer and dry layer which were confirmed by formation testing in all blocks, then it has been applied in more than 2000 wells in Jianghan oilfield in which its interpretation coincidence rate is above $85 \%$. It is more adaptable than the traditional methods and the interpretation coincidence rate has increased by $10 \%$. It is an effective way for oil and gas logging evaluation [10]. It plays an important role in evaluation of unconventional hydrocarbon zone such as lowresistivity reservoirs, fracture reservoirs and shale gas layers especially in weak show of oil and gas. Well A is a preliminary exploration shale gas well which is near the southwest axial line at the northern high of Jiannan structure in the middle of Shizhu synclinorium. Well B is at the southern high of Jiannan structure in the middle of Shizhu synclinorium. Well $\mathrm{C}$ is a preliminary exploration well which lies in Jinjiawan fault block of Mawangmiao nose structure of 
Qianjiang depression in Jianghan Basin. Taking these 3 wells as examples, RROP- $\mathrm{K}_{\mathrm{c}}$ crossplot is used to evaluate oil and gas shows in gas logging. The conclusions of gas logging interpretation, oil testing and gas testing are coincident. It indicates that the method has obvious advantages in evaluating different hydrocarbon reservoirs.

\section{Case 1: Well A-C The Test Well of Shale Gas in the Western Hubei and Eastern Chongqing Area}

The primary objective interval of the shale gas reservoirs in Western Hubei Eastern Chongqing area is in Dongyuemiao Formation of Jurassic artesian well group. Dongyuemiao Formation buries from 500.0 to $1000.0 \mathrm{~m}$, which lithology is primarily dark gray mudstone and grey black shale. It is proved by year's exploration that Dongyuemiao Formation is the favourable zones of rich oil and gas in Western Hubei Eastern Chongqing area. Dongyuemiao is given priority to half deep lake deposition with abnormal gas logging in mud shale in several wells, which characterizes unconventional shale gas reservoir. In an old well adjacent to Well A, some phenomena occurred in the drilling: gas contamination is severe, ditch surface increases and spills over, gas flame is blue. According to the North American shale gas exploration experience and contrast of the shale gas key indicators, many domestic experts believe that choosing Dongyuemiao Formation as the shale gas exploration and development area has high success rate.

The standards of Region I, II, III for shale gas reservoirs in the western Hubei and eastern Chongqing area are: Region I indicates hydrocarbon reservoirs in which drilling time ratio is greater than or equal to 1.5 and hydrocarbon contrast coefficient is greater than or equal to 8; Region II indicates hydrocarbonaceous water layer which drilling time ratio is greater than 1.5 and hydrocarbon contrast coefficient is less than 8; Region III indicates dry layer in which drilling time ratio is less than 1.5 [11].
Well A is the first test well of Jianghan oilfield for shale gas. In mud logging operation, with RROP-K $\mathrm{K}_{\mathrm{c}}$ crossplot interpretation, 2 intervals were gas zones which thickness was $50.0 \mathrm{~m}$ (Fig. 2) in Dongyuemiao section of the lower Jurassic Ziliujing formation. The lithology of 598.0-646.0m interval was grey black shale and mudstone which total hydrocarbon was from $0.11 \%$ to $9.85 \%, \mathrm{C}_{1}$ from $0.02 \%$ to $8.14 \%, \mathrm{C}_{2}$ from $0 \%$ to $1.09 \%, \mathrm{C}_{3}$ from $0 \%$ to $0.31 \%, \mathrm{iC}_{4}$ from $0 \%$ to $0.04 \%$, $\mathrm{nC}_{4}$ from $0 \%$ to $0.08 \%$, drilling time from $2 \mathrm{~min} / \mathrm{m}$ to 3 $\mathrm{min} / \mathrm{m}$, hydrocarbon contrast coefficient from 16 to 89 , drilling time ratio from 1.5 to 2.5 . The total hydrocarbon curve was trapezoid. The drilling fluid density fell from $1.10 \mathrm{~g} / \mathrm{cm}^{3}$ to $1.07 \mathrm{~g} / \mathrm{cm}^{3}$, viscosity rose from $60 \mathrm{~s}$ to $80 \mathrm{~s}$, no significant changes in chloride ion content $(3545 \mathrm{~g} / \mathrm{l})$, no changes in ditch surface and pit volume. The Interpretation result of RROP- $\mathrm{K}_{\mathrm{c}}$ crossplot was gas zone.

After well completion, large scale fracturing was carried out in 610.0-646.0m interval to obtain industry gas flow which test production reached $2200 \mathrm{~m}^{3} / \mathrm{d}-3925 \mathrm{~m}^{3} / \mathrm{d}$ and formal constant rate of production was $2700 \mathrm{~m}^{3} / \mathrm{d}$. One year later its stable yield was $2300 \mathrm{~m}^{3} / \mathrm{d}$ and annual gas production exceeded $70 \times 10^{4} \mathrm{~m}^{3}$. The success of this well shows favorable exploration prospect of shale gas in the western Hubei and eastern Chongqing area.

\section{Case 2: Well B-_The Exploratory Well of Tight Car- bonate Reservoir in the Eastern Sichuan Area}

The main target zones of tight carbonate reservoir in east Sichuan area is Permian Changxing formation, limestone of Triassic Feixianguan group and dolomite reservoir, which lithology is grain limestone and pore dolomite. Because this kind of reservoir has low porosity, poor permeability and undeveloped fractures, horizontal well development is needed and large hydraulic fracturing should be carried out to obtain industrial oil and gas flow. Reservoirs in Changxin group and Feixianguan group have stable lateral distribution in the structure, and the gas reservoir has obvious "overall

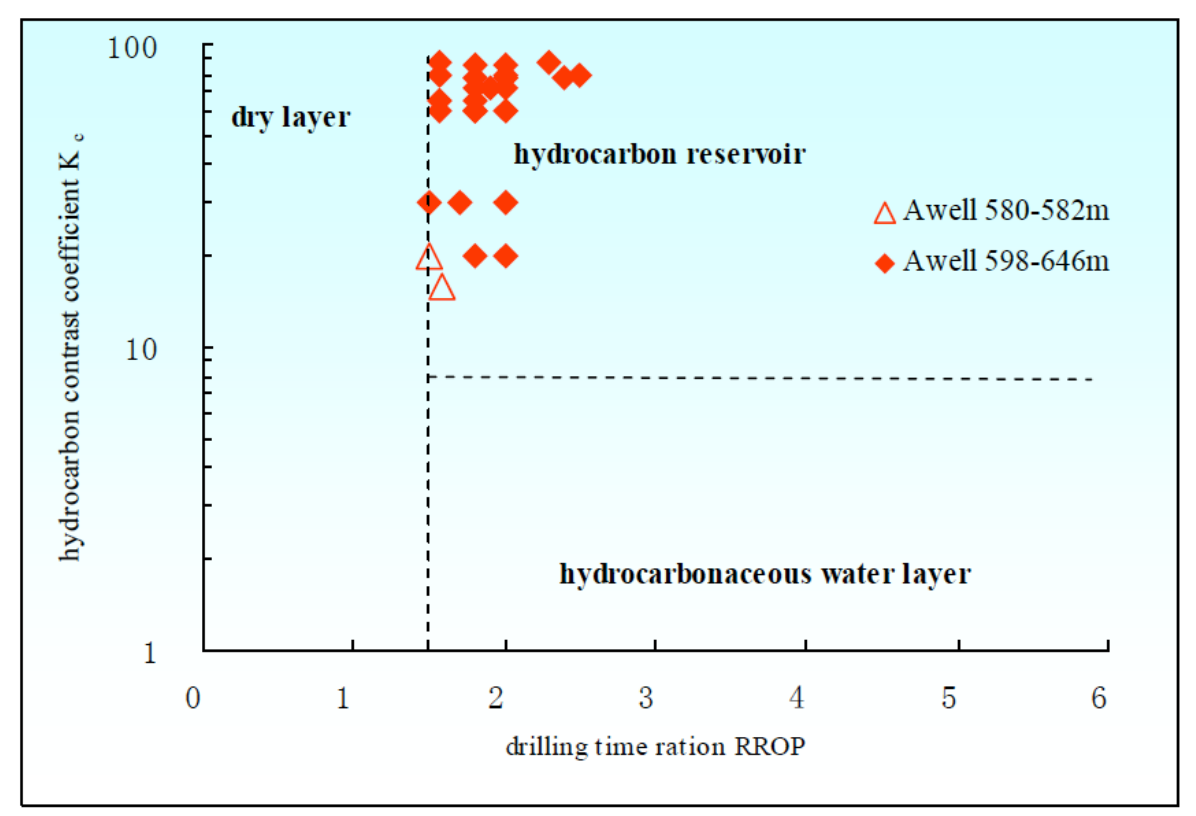

Fig. (2). Application example of well A. 
gas distribution and local enrichment" characteristics. Being poor reservoir physical property, low rock permeability, high heterogeneity, single well in the fracture development parts often has high capacity, which is sometimes the favorable efficient development area. Exploration practice has proved that gas logging is the important method to find gas shows in the tight carbonate reservoirs in the area. It has low cost and good result.

The interpretation standards of region I, II, III for Permian Changxin formation and Triassic Feixianguan sea facies tight carbonate reservoirs in the eastern Sichuan area are: Region I indicates hydrocarbon reservoir which drilling time ratio is greater than or equal to 1.2, hydrocarbon contrast coefficient is greater than or equal to 8; Region II indicates hydrocarbonaceous water layer which drilling time ratio is greater than 1.2 , hydrocarbon contrast coefficient is less than 8; Region III indicates dry layer which drilling time ratio is less than 1.2.

When logging in Well B, abnormal indication of oil and gas was found in 7 intervals of tight carbonate rocks which thickness was $171.0 \mathrm{~m}$. With RROP-K $\mathrm{K}_{\mathrm{c}}$ cross-plot interpretation 4 intervals were gas zones which thickness were $112.0 \mathrm{~m} ; 2$ layers were dry layers (gas-bearing beds) which thickness was $29.0 \mathrm{~m}$ and 1 layer was hydrocarbonaceous water layer which thickness was $30.0 \mathrm{~m}$ (Fig. 3). The lithology in 3578.0-3635.0m interval was stable with mainly limestone. The total hydrocarbon rose from $0.04 \%$ to $1.75 \%$, $\mathrm{C}_{1}$ from $0.04 \%$ to $1.38 \%$, and the other components was 0 . The drilling time was in $15 \mathrm{~min} / \mathrm{m}-18 \mathrm{~min} / \mathrm{m}$. The average hydrocarbon contrast coefficient was 18.5, average drilling time ratio was 3 . The $\mathrm{POR}-\mathrm{K}_{\mathrm{c}}$ crossplot interpretation result was gas zone.

After well completion, Ignition at the flare stack was successful when acid fracturing operations were carried out in $3578.0-3635.0 \mathrm{~m}$ and $3668.0-3674.0 \mathrm{~m}$ intervals. Initial flame height was $6-8 \mathrm{~m}$ and the highest flame reached $15 \mathrm{~m}$. Then test gas began after continual blowing off for 12 hours. Daily stable yield of natural gas was $9.56 \times 10^{4} \mathrm{~m}^{3} / \mathrm{d}$. Interpretation conclusion corresponds with the oil testing result.

\section{Case 3: Well C_- The Exploratory Well of Tight Sand- stone Reservoir in Mawangmiao Structure of Jianghan Basin}

The main target strata of Mawangmiao structure are the tight sand strata in lower segment I, II, III of Xingouzui formation, which depth is from is $700.0-1000.0 \mathrm{~m}$, oilbearing area is $10 \mathrm{~km}^{2}$, and proven geological reserves is $1800 \times 10^{4} \mathrm{t}$. It is the largest oilfield of Xingouzui formation in Jianghan oilfield. Xingouzui formation in Mawangmiao oilfield deposit in the delta front and offshore shore and shallow lake beach facies, which sedimentary microfacies can be subdivided into the sedimentary microfacies combination characteristics and sequence of underwater distributary channel, mouth bar, far bank sand bar and distributary bay, etc. The reservoir is terrigenous clastic sedimentary with lithology of dominant fine siltstone which belongs to feldspar quartzy sandstone with the median size of $0.03 \mathrm{~mm}$ to $0.09 \mathrm{~mm}$ and medium separation. Cementation type is given priority to pore cementation and then contact - pore cementation. The oil layers have poor physical property with medianlow porosity, low permeability, which needs to be rebuilt by fracturing to achieve productive capacity.

The interpretation standards of region I, II, III for the tight sand reservoirs of low segment I, II, III of oil-bearing formation of Xingouzui group of Mawangmiao structure are: Region I indicates hydrocarbon reservoir which drilling time ratio is greater than or equal to 1.5 and hydrocarbon contrast coefficient is greater than or equal to 4; Region II

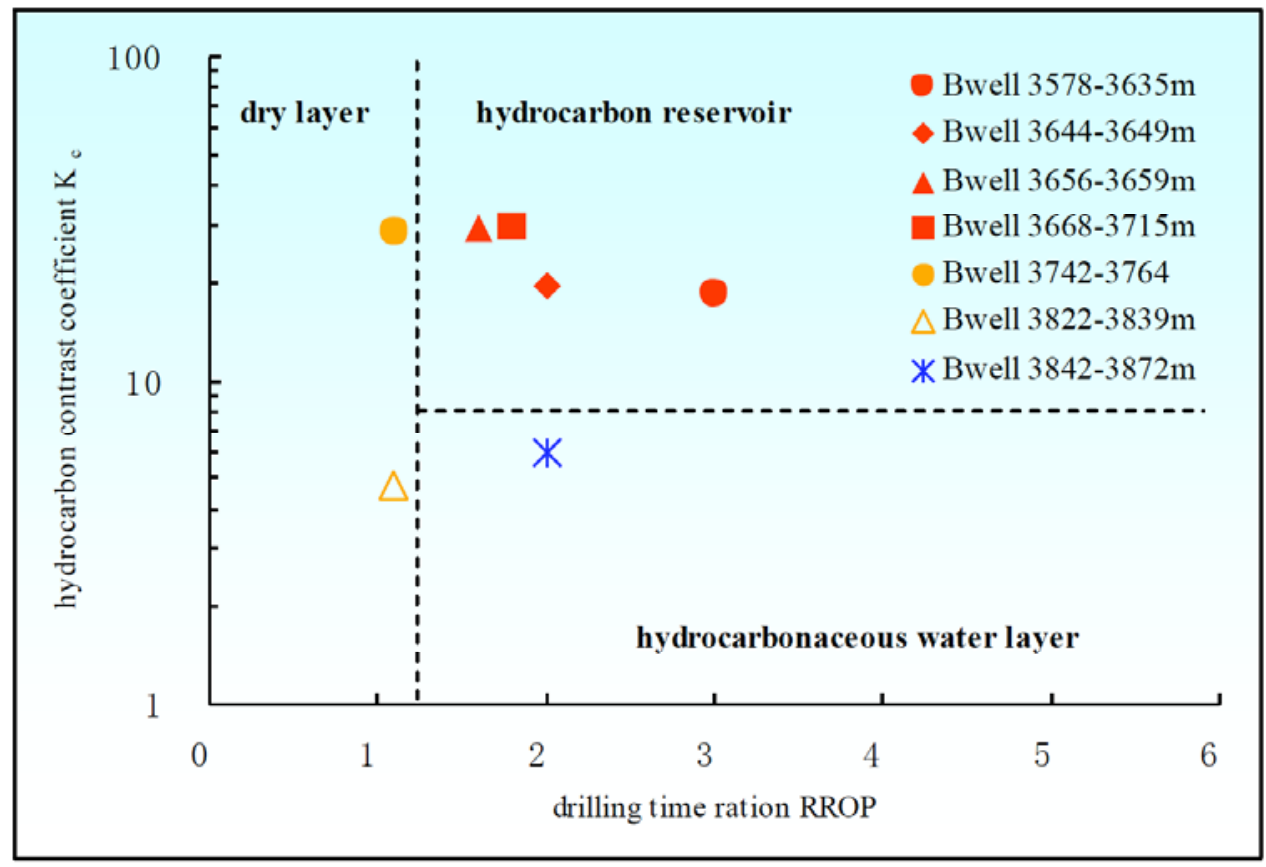

Fig. (3). Application example of well B. 


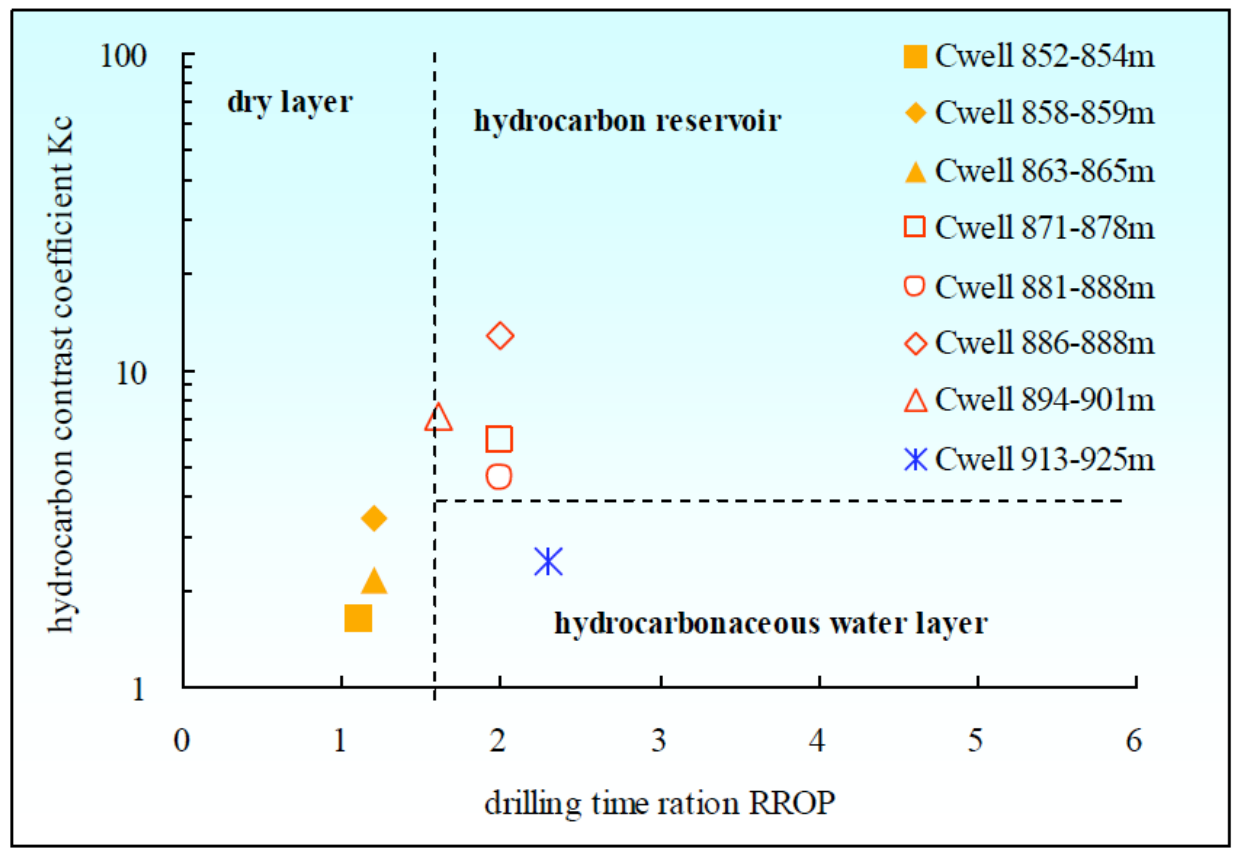

Fig. (4). Application example of well C.

indicates hydrocarbonaceous water layer which drilling time ratio is greater than 1.5 and hydrocarbon contrast coefficient is less than 4; Region III indicates dry layer which drilling time ratio is less than 1.5.8 abnormal show layers of tight sand were found in Well C, and the thickness was $35.0 \mathrm{~m}$. With RROP-K $\mathrm{K}_{\mathrm{c}}$ crossplot interpretation, 4 layers were oil reservoirs which thickness was $18.0 \mathrm{~m}, 3$ layers were dry layers which thickness was $5.0 \mathrm{~m}, 1$ layer was hydrocarbonaceous water layer which thickness was $12.0 \mathrm{~m}$ (Fig. 4). The lithology in interval $884.0-888.0 \mathrm{~m}$ was taupe oil-stained siltstone which total hydrocarbon rose from $0.10 \%$ to $1.36 \%, \mathrm{C}_{1}$ from $0 \%$ to $0.02 \%, \mathrm{C}_{2}$ was $0 \%, \mathrm{C}_{3}$ from $0 \%$ to $0.004 \%, \mathrm{iC}_{4}$ from $0 \%$ to $0.008 \%, \mathrm{nC}_{4}$ from $0 \%$ to $0.004 \%$; the drilling time was between $2 \mathrm{~min} / \mathrm{m}-3 \mathrm{~min} / \mathrm{m}$.

The average hydrocarbon contrast coefficient was 13; average drilling time ratio was 2 . RROP- $\mathrm{K}_{\mathrm{c}}$ cross-plot interpretation result was oil layer.After well completion, oil testing of interval $884.0-891.0 \mathrm{~m}$ was $15.7 \mathrm{t} / \mathrm{d}$. Crude analysis: density was $0.8735 \mathrm{~g} / \mathrm{cm}^{3}$, viscosity was $20.64 \mathrm{mPa}$.S. Interpretation conclusion corresponds with oil testing result.

\section{FINDING}

1) Unconventional oil and gas needs to be developed through the overlength horizontal wells that are costly and high risk. LWD (logging-while-drilling) technology can quickly find and evaluate unconventional oil and gas shows during drilling. It can reduce the drilling risk and improve the overall benefit of unconventional oil and gas exploration and development.

2) When using RROP- $K_{c}$ crossplot, reading the measured values of gas-log drilling time, total hydrocarbon and hydrocarbon component needs to avoid the effect caused by the change of bits and mud systems, and to avoid the effect of gas logging instrument malfunction and engineering accident handling.

3) RROP- $K_{c}$ crossplot interpretation is a simple and fast interpretation method for gas logging, and it's suitable for evaluation of anomalous oil and gas show during drilling.

4) In identification and evaluation of unconventional hydrocarbon zone such as low- resistivity reservoir, fracture reservoir and shale gas zone, RROP $-\mathrm{K}_{\mathrm{c}}$ crossplot interpretation method has unique technical advantages. It has wide applicability and high accuracy and can not be replaced by other logging interpretation means.

5) It is found in study of RROP- $K_{c}$ crossplot that the logarithmic ratio of drilling time has linear correlation with total porosity, and the hydrocarbon ratio and reservoir water saturation of 2.0-3.3 times square are in inverse proportion.

\section{CONFLICT OF INTEREST}

The authors confirm that this article content has no conflict of interest.

\section{ACKNOWLEDGEMENTS}

We sincerely acknowledge the anonymous reviewers whose correlations and comments have greatly improved the manuscript. This research work was supported by National Natural Science Foundation of China (No. 41404084), Natural Science Foundation of Hubei Province of China (No. 2013CFB396).

\section{REFERENCES}

[1] Energy Information Administration, US Crude Oil Production, Imports \& Exports, May 2012. Available from: http:// 
www.eia.gov/dnav/pet/pet_move_wkly_dc_nus-z00_mbblpd_ 4.htm [Accessed: $12^{\text {th }}$ April, 2013]

[2] Ledingham, W. Glen, and S. Pool, "Geological note", AAPG Bulletin, vol. 31, pp. 2063-2067, 1947.

[3] Energy Information Administration, "Annual Energy Outlook 2012”, February 2012. Available from: http://www.eia.gov/ todayinenergy/detail.cfm?id=4910 [Accessed: $12^{\text {th }}$ April, 2013]

[4] The Unconventional Oil Subgroup of the Resources \& Supply Task Group, Potential of North American Unconventional Oil resource, Working Document of the NPC North American Resource Development Study, 2011.

[5] National Resources Canada, "North American Tight Oil", May 2012. Available from: http:/ /www.nrcan.gc.ca/energy /sources /crude /2114\#oil1 [Accessed: $12^{\text {th }}$ April, 2013]

[6] National Energy Board, "Tight Oil Developments in the Western Canada Sedimentary Basin", December 2011. Available from: http://www.neb-one.gc.ca/clf-nsi/rnrgynfmtn/nrgyrprt///tghtdvlpm ntwcsb2011/tghtdvlpmntwcsb2011-eng.html [Accessed: $12^{\text {th }}$ April, 2013]
[7] Z. Qingfan, and Y. Guofeng, "Definition and application of tight oil and shale oil terms", Oil \& Gas Geology, vol. 33, pp. 541-544, 2012.

[8] X. Shikuang, and S. Yuanhui, "Research of the compound logging interpretation for show of oil and gas in jianghan oilfield", Jianghan Petroleum Staff College Transaction, vol. 19, pp. 34-36, 2006.

[9] W. Bin, Z. Daqing, and C. Feiyan, "Development and application of the crossplot for gas logging interpretation in cainan area", Mud Logging Engineering, vol. 16, pp. 9-12, Jan. 2005.

[10] S. Yuanhui, "The mud logging interpretation method for tight sand reservoirs in the low-permeability oilfield", In: Logging Professional Committee of Hubei Institute of Petroleum. Unconventionality Oil and Gas Logging Technology Symposia, Yangtze University Press: China 2006, pp. 45-51.

[11] S. Wenrui, W. Rong, and H. Qiang, "Study on well logging interpretation and evaluation of the shale gas in the western hubei and eastern sichuan area", Mud Logging Engineering, vol. 23, pp. 25$28,2012$.

Received: October 07, 2014

Revised: January 19, 2015

Accepted: June 23, 2015

(C) Shi et al.; Licensee Bentham Open.

This is an open access article licensed under the terms of the Creative Commons Attribution Non-Commercial License (http://creativecommons.org/licenses/by-nc/3.0/) which permits unrestricted, non-commercial use, distribution and reproduction in any medium, provided the work is properly cited. 